\title{
Impact of Smoking and Smoking Cessation on Periodontal Health: A Review
}

\author{
Dr. Khushboo Goel, ${ }^{1}$ Dr. Ranjita Shrestha Gorkhali, ${ }^{2}$ Dr. Shaili Pradhan, ${ }^{2}$ Dr. Sujaya Gupta ${ }^{3}$ \\ ${ }^{1}$ Department of Periodontology \& Oral Implantology, College of Dental Surgery, B.P. Koirala Institute of Health Sciences, Dharan, Nepal \\ ${ }^{2}$ Department of Dental Surgery, Periodontics Unit, National Academy of Medical Sciences, Bir Hospital, Kathmandu, Nepal, \\ ${ }^{3}$ Department of Periodontics, Kantipur Dental College, Kathmandu, Nepal.
}

\begin{abstract}
Tobacco use persists as a chronic global public health concern. The deadly habit affects almost all organs of the body including the oral and periodontal structures. Smoking is established as one of the major preventable etiological risk factors for the initiation and progression of periodontitis. The habit dependence typically requires a continuous assessment and repeated intervention. Emerging evidence has suggested the benefit of smoking cessation on periodontal health that trends for greater probing depth reductions and a favorable response to treatment outcomes. The dental settings are now increasingly being recognized as a place to target patients to quit or even prevent the initiation of smoking habit. The dental practitioner and the periodontal specialist may, therefore play a pivotal role by the inclusion of smoking cessation programs in their daily practice and reduce the major risk involving oral tissues and the systemic health. This review addresses the impact of smoking on periodontal tissues, the effect of smoking cessation protocols to improve periodontal health and the role of professionals in cessation.
\end{abstract}

Keywords: Periodontal disease; periodontitis; risk factor; smoking; tobacco; tobacco cessation.

\section{INTRODUCTION}

Tobacco use is a preventable major risk factor for a variety of systemic diseases and oral disorders such as cancer and periodontal diseases. ${ }^{1,2}$ According to World Health Organization (WHO) report on global tobacco epidemic 2017, approximately 7 million people are killed by tobacco worldwide, which burdens the world's economy by 1.4 trillion dollars each year. Around 8,90,000 non-smokers are killed by being exposed to second-hand smoking. In Nepal, the situation is even more alarming as the prevalence rate of current tobacco smoking in 15 years and older is $10.3 \%$ in female and $27 \%$ in male and the daily tobacco users account for $15.8 \%$. Nepal has one of the highest proportions of female smokers in the world with a noticeable impact on maternal and child health. Overall, the number of tobacco smokers worldwide will reach an estimated 1.1 billion by 2025. ${ }^{3}$ In addition, the use of smokeless tobacco as a possible substitute for smoked tobacco products remains an area of controversy and public health debate.

\section{Correspondence:}

Dr. Khushboo Goel

Department of Periodontology\&OralImplantology, College of Dental surgery, B.P. Koirala Institute of Health Sciences, Dharan, Nepal. email: khushboo.goel@bpkihs.edu

\section{Citation}

Goel K, Gorkhali RS, Pradhan S, Gupta S. Impact of smoking and smoking cessation on periodontal health: a review. J Nepal Soc Perio Oral Implantol. 2017;1(2):65-71.
Tobacco contains addictive substances and all of its products are harmful. It harms almost every organ of the body as it contains more than 7000 chemicals, of which at least 250 are known to be harmful and at least 69 are known to cause cancer. The substances include poisons (e.g. carbon monoxide), toxic substances (e.g. oxidizing radicals), carcinogens (e.g., nitrosamines) and addictive psycho-active substances such as nicotine. Nicotine is a pharmacologically active alkaloid, responsible for the dependence that characterises the smoking habit. It affects the dopamine systems in the smoker's brain and increases the number of nicotinic receptors. Nicotine is rapidly absorbed into the bloodstream, through the oral mucosa and reaches the brain within 10-19 seconds. The smoker's brain and body become used to functioning on a certain level of nicotine. If a person stops smoking, the level of nicotine drops which will cause them to crave nicotine (cigarettes) and have withdrawal symptoms. Cigarettes are the main product smoked; others exposures include bidis, kreteks (clove cigarettes) and cigars, pipes as water pipes (hookahs, bhangs, narghiles, shishas), sulfa, chillum, and kankad and non-combusted or "smokeless" tobacco products for chewing and holding in the mouth or placing in the nose. Four major forms of smokeless tobacco are chewing tobacco, snuff (moist or dry), Swedish snus and gutkha. The other forms of smokeless tobacco products common in South-East Asia and commonly in Nepal are surti leaves, khaini, mawa, paan , zarda, pan masala, and gudakhu. ${ }^{4}$ There is extensive and consistent evidence showing 
the harmful effects of tobacco use in the form of smoking on oral health. There is a strong dose-response relationship between smoking tobacco and development of pre-cancerous conditions, oral cancer ${ }^{5}$ and progression of periodontal diseases. ${ }^{6}$ Approximately $42 \%$ of periodontitis cases can be attributed to smoking. ${ }^{7}$ As per WHO global report 2017, the prevalence of tobacco use amongst the youth in Nepal is on a rise with $7.2 \%$ in the form of current users and $5 \%$ in the form of daily users. It therefore seems prudent to target young adult non-smokers in initiating the habit and to help quit smokers who have only recently taken up the habit. Authors confirm that quitting smoking helps reduce the risk of oral cancer by $50 \%$ in five years ${ }^{8}$ and reduction of up to $12 \%$ in the number of cases of the destructive periodontal disease. ${ }^{9}$ Owing to this significant impact on both oral and periodontal health, this study is aimed at reviewing the impact of tobacco use on periodontal tissues, the impact of smoking cessation to improve periodontal health and to benefit from the results of periodontal treatment.

\section{Impact of smoking and its products on periodontal tissues}

Tobacco use in the form of smoking is an independent, well-established and, second to bacterial plaque, the strongest modifiable risk factor for periodontal diseases. Epidemiological studies suggest a strong association with the history that dates back to 1859. It was Pindborg in 1947 that suggested a high prevalence of acute necrotizing ulcerative gingivitis in smokers. ${ }^{10}$ There exist a robust evidence of adverse effects of tobacco on initiation and progression in periodontal tissues as well ${ }^{11,12}$ and is considered a major impediment in response to therapy. ${ }^{13}$ The destructive effects of smoking appear clinically in terms of less gingivitis, lower gingival bleeding, deeper probing depths, ${ }^{14}$ two to eightfold increase in periodontal attachment loss, ${ }^{15}$ significant alveolar bone loss, ${ }^{16,17}$ and tooth loss. ${ }^{18,19}$ This is seen even after adjustment of confounding variables, such as age, plaque, calculus, gender, and socioeconomic status when compared to non-smokers. The effect of smoking on the subgingival calculus load and the probability of having an advanced periodontal disease is dose-dependent. Both daily consumption quantity and duration of smoking are related..$^{20}$ Smoking has been also acknowledged as a predisposing factor in implant failure. Smokers experience approximately twice the failure rate based on a variety of implant designs and surfaces..$^{21}$ Below we discuss the summary of the plausible causes that smoking has on the periodontium.

\section{Biologic events and causes}

1. Impact on pocket microflora: Effect of smoking on the host tissues could result in a different microflora in the pocket. Conflicting results exist in terms of prevalence ${ }^{22}$ and amount of bacteria in the subgingival microbiota in smokers compared to non-smokers. Some authors report no differences ${ }^{23,24}$ and some have shown to harbor higher proportion of putative periodontal pathogens, particular in the palatal aspects of the maxillary teeth and the upper and lower incisor regions. ${ }^{25}$ The pocket oxygen tension was significantly lower in smokers compared with non-smokers which also might be a probable factor associated with pocket microflora. ${ }^{26}$ The impact of tobacco use on the oral microbiome remains an active area of research as there is greater extent of colonization even in shallow pocket depths..$^{27,28}$

2. Effect on gingival vasculature: Smoking has a longterm suppressive effect with changes in the proportion of blood vessels. This impacts the blood flow and vascularity of periodontal tissues. There is lower bleeding on probing with less redness of gingival tissues. This may occur owing to fewer vessels visible clinically and histologically. ${ }^{29}$ Mirbod et al. showed a higher percentage of smaller blood vessels than large but with similar vascular density. ${ }^{30}$ However, results suggested that the inflammatory response in smokers with periodontitis may not be accompanied by an equivalent increase in vascularity.

3. Host Response: The evidence for smoking's deleterious effect on the host response is much stronger; as it affects local and systemic immune and inflammatory responses. Polymorphonuclear cells (PMN) are the fundamental cells of defence in the periodontal tissues. The continual exposure to smoke impairs the progression of neutrophils into the periodontal pocket. Besides, there is also a shift in the function of neutrophils toward destructive activities that includes induction of protease release (elastase and matrix metalloproteinase), ${ }^{31}$ impaired phagocytosis, chemotaxis when exposed to acute levels of tobacco smoke, neutrophil priming (hyper-reactivity), ${ }^{32}$ upregulation of molecules such as ICAM-1 and thus soluble ICAM-1 on endothelium that interfere with the normal receptor ligand binding and function of the leukocyte in defence. ${ }^{33,34}$ The positive effect is that and there is evidence that the subject may return to more normal levels after quitting smoking.

Smoking exhibits negative effects on cytokine and growth factor production. Mechanisms of which still remain unclear and contradictory as higher levels of TNF- $\alpha$ and IL- 8 was observed in the gingival crevicular fluid of smokers compared to nonsmokers. ${ }^{35}$ In contrast, pro- and anti-inflammatory 
cytokines have been reported to be lower in association with smoking and its compounds. It seems that cigarette smoke contains potent inhibitors of both gene expression and protein production, at least for IL-1 $\beta$, IL-8, IL-2 and TNF- $\alpha .{ }^{36}$ Smoking may have a direct effect on bone loss in periodontitis. The results are still inconclusive. A study was done by Cesar-Neto et al. in 2007 mentioned that cigarette consumption may favor bone resorption through increased ratios of IL-6: IL-10 and RANKL: osteoprotegerin (OPG) in periodontal tissues and through suppression of serum OPG production. ${ }^{37}$ It was, therefore concluded that smoking modulation of bone destruction in periodontal disease may involve reduced levels of anti-inflammatory and antiresorptive factors such as IL-10 and OPG, respectively, and may also involve high levels of pro-inflammatory cytokines such as IL-6 and IFN- $\gamma$.

Impairment in antibody responses and cellular immune responses has been observed. Smoking appears to affect both $\mathrm{B}$ and $\mathrm{T}$ cell function, inducing functional unresponsiveness in $\mathrm{T}$ cells. There is a reduced serum $\operatorname{IgA} \operatorname{IgG}\left(\operatorname{IgG}_{2}\right)$ levels $^{38}$ that decreases the resistance of tissues and shows greater tendency for periodontal tissue breakdown. There is reduced number and cytolytic activity of circulating natural killer cells has been observed that may increase the risk for malignancy. ${ }^{39}$ Tobacco products have been shown to impair the reparative abilities of cells of the periodontium and inhibit gingival and periodontal ligament (PDL) fibroblasts growth, ${ }^{40}$ attachment and collagen production. Root surfaces of teeth extracted from smokers show reduced PDL fibroblast attachment as compared to those from non-smokers. ${ }^{41}$

Nicotine is just one of the toxic compounds of cigarette smoke and with various others components, tobacco may impose detrimental effects on inflammatory, immunological and vascular cells. Factors seemingly contribute to increased tissue destruction, thereby affecting the vasculature and revascularization. This undoubtedly impairs the healing response as well as delays healing. A large body of published evidence reports the adverse effects of tobacco use in all aspects of periodontal treatment including non-surgical treatment, ${ }^{42-44}$ periodontal surgeries ${ }^{45}$ including effects on furcation treatments, ${ }^{46}$ regenerative surgeries (bone grafts, ${ }^{47}$ and guided tissue regeneration ${ }^{48}$ ) mucogingival plastic periodontal surgery, ${ }^{49}$ implant placement, ${ }^{49}$ implant survival in sites treated by bone augmentation procedures, ${ }^{50}$ maintenance therapy ${ }^{51}$ and in refractory periodontitis.

Similar effects and risks of cigarette smoking are observed with cigars, pipe smoking and smokeless tobacco consumption to the periodontium. Prevalence of moderate to severe periodontitis and higher extent of attachment loss, recession ${ }^{52}$ and tooth $\operatorname{loss}^{53}$ was observed similar to current smokers Hookah, a form of tobacco water pipe smoking, also appears to be associated with impaired periodontal health. ${ }^{54}$ Smokeless tobacco is well known to induce wrinkled changes in the oral mucosa at site where quid is placed. A marked loss of the periodontal attachment and gingival recession has been observed near the area where the smokeless tobacco products are placed. ${ }^{55}$ Studies also indicate a greater overall prevalence of severe active periodontal disease. ${ }^{56}$ In addition, smokeless tobacco use has also been associated with greater risk of oral, esophageal, and pancreatic cancer. ${ }^{57}$ A significant impact of almost all tobacco products has been observed that provides us with a strong rationale for targeting smoking prevention and smoking cessation programs for all tobacco users. The evidence is further supported by the data emanating from patients who stop smoking and improvement in their general and periodontal health.

\section{Impact of smoking cessation on periodontal tissues}

Smoking cessation cannot reverse the past effects of smoking; however, the clinical and histological evidence demonstrates that negative effects on periodontal tissues may be reverted. ${ }^{14}$ An increase in gingival blood flow after smoking cessation was observed with Laser Doppler flowmetry. ${ }^{58}$ The rate of bone and attachment loss slows and the severity falls between the clinical values reported in smokers and non-smokers. ${ }^{13}$ The risk for periodontitis and tooth loss ${ }^{59,60}$ decreases with increasing number of years since quitting smoking ${ }^{7,61}$ and improvement in healing phase. ${ }^{62}$ Implant success rates for past smokers are similar to those for never smokers. The treatment response in terms of clinical and microbiological variables to non-surgical mechanical therapy yielded a result comparable to that of non-smokers ${ }^{43,63,64}$ along with a critical role of cessation in altering the subgingival biofilm. ${ }^{65}$ The beneficial effect was observed post periodontal surgeries ${ }^{66}$ as well as better response and success rates after regenerative and Implant procedures respectively. ${ }^{21}$

\section{Role of dental professionals in discouraging the deadly habit}

Dental and periodontal literature is replete with data with long term detrimental effect of smoking and a relatively rapid improvement in the periodontium on its cessation of periodontal health. Both the general practitioner and the periodontal specialist will encounter tobacco users more frequently among their patients than in the general population. ${ }^{11}$ However, dentists, in general, have not widely embraced tobacco cessation in practice. ${ }^{67}$ In actuality, 
current adult smokers are far less likely to receive advice to quit when visiting a dentist than a physician. ${ }^{68}$ Owing to have known the impact on both oral and general health, introduction of smoking cessation training into the curriculum at many dental schools and in the education of dental hygienists needs to be implemented. The overall goal of addressing the problem of tobacco use and periodontal disease should not be a reduction in tobacco use, but an effective long-term tobacco cessation program. ${ }^{69}$ At a minimum, these three primary cessation interventions should be included in a comprehensive tobacco control programme.

(i) Behavioral therapy in the form of cessation advice in primary health care systems increases quit rates by about 3\%.70 A recommended general framework in 5 "A" is underlined that is emphasized for the patients who are willing to quit (Table 1). In recent years, this has been condensed to Assist, or an $\mathrm{ABC}$ Model: Ask to provide Brief advice and Cessation support. ${ }^{71}$ Brief tobacco dependence advice is considered highly effective by any health professional during their routine office visits and may provide counselling which may be as brief as 3 minutes. There exists two components of counselling, and the clinicians should use these when the counselling patients are attempting to quit:

\section{- Practical counselling (problem solving/skills training) \\ Social support delivered as part of treatment}

(ii) Quit lines and cessation advice through free telephone help lines which are estimated to increase quit rates by about $4 \% .70$ Quit lines may also be provided via emails and fax (known as quit lines), which may be in single or multi-session counselling. The benefit is that information may be tailored to specific populations (i.e., pregnant women, smokeless tobacco users, different age groups)..$^{72}$ The interventions can also include mobile technology to provide personalized smoking cessation advice. $^{73}$

(iii) Pharmacological management: There are several evidence-based pharmacological treatments for tobacco dependence. Nicotine Replacement Therapy (NRT) is one of the popular treatments. It comes in different formulations, for example, chewing gum (2 $\mathrm{mg}$ is equal to 1-24 cigarettes/day or $4 \mathrm{mg}$ preparation up to 12 weeks), transdermal patch (7 mg and $22 \mathrm{mg}$ of nicotine over a 24-hour period), nasal spray (8-40 doses/day for 3-6 months), inhaler and sublingual tablets/lozenges which are over-the-counter products and thus easily accessible. NRTs increase the rate of quitting by 50 to $70 \%$, regardless of setting and are independent of the intensity of additional support. ${ }^{74}$ It reduces many of the physiological and psychomotor withdrawal symptoms usually experienced following smoking cessation and may, therefore, increase the likelihood of remaining abstinent. ${ }^{75}$ Medication which is prescribed when NRT fail or given in combination with NRT are bupropion, varenicline, nortriptyline, clonidine, methoxsalen, and rimonabant. These drugs have proven to double the rate of quitting, by managing the addiction and treating the anxiety associated with quitting and its consequences.

It is the duty of every clinician to encourage patients willing to make a quit attempt. For the patients who are not willing to quit require brief motivational interventions. It may be beneficial to have a training organized for the clinical staffs in motivational interviewing. The content areas that should

Table 1: 5 A's model for helping patients quit using Tobacco.

\begin{tabular}{|l|l|}
\hline \multicolumn{1}{|c|}{ Strategy } & \multicolumn{1}{c|}{ Action } \\
\hline Ask & Ask all patients about tobacco use at every visit and record their status \\
\hline Advise & $\begin{array}{l}\text { Advise in a clear, strong and personalized manner every tobacco users to stop using tobacco and } \\
\text { non-tobacco users to remain tobacco-free }\end{array}$ \\
\hline Assess & Ask if tobacco user is willing to quit within the next 30 days \\
\hline Assist & Help all tobacco users to stop based on their willingness to quit with a quit plan \\
\hline Arrange & Schedule follow-up contact, either in person or by telephone \\
\hline
\end{tabular}

Table 2: 5 R's model for patients not willing to quit tobacco use.

\begin{tabular}{l|ll} 
Strategy & Action
\end{tabular}

Relevance Encourage the patient to indicate why quitting is personally relevant, being as specific as possible

\begin{tabular}{l|l} 
Risk & Ask the patient to identify potential negative consequences of tobacco use and suggest and highlight those
\end{tabular} Risk that seem most relevant to the patient

Rewards Ask the patient to identify the potential rewards of stopping tobacco use

Roadblocks Ask the patient to identify barriers to quitting and note elements of treatment

Repetition Repeat motivational intervention every time 
be addressed in a motivational counselling intervention can be captured by the " 5 R's": relevance, risks, rewards, roadblocks, and repetition. Research suggests that the " 5 R's" enhance future quit attempts ${ }^{71}$ (Table 2). While there is no reason to reduce our efforts to improve oral hygiene in our patients there is a significant need also to address the issue of smoking cessation in the management of periodontitis. Helping your patients quit is the best thing that we can do to improve their health. We are in a unique and privileged position to extend the patient's life up to 10 years by asking them to quit and directly reduce the risk. ${ }^{76}$

In context to Nepal, the goal to achieve a tobacco free country is a long way. The smoking cessation services are only available in some health facilities and services like toll free telephone quit line/helpline, NRT and materials are not available. The treatment of tobacco dependence is almost negligible. However, the government of Nepal is making its sincere efforts through implementing some regulations in the Tobacco Control Act. This Act has already banned smoking in public places (effective since August 2011). Nepal introduced the world's largest health warnings on tobacco packaging surfaces (covering 90\% of the package) in May 2015. On March 14, 2017, the government enforced the provision of acquiring a license to sell tobacco and tobacco products (yet to come into practice) and has plans to introduce plain cigarette packaging by 2018 and make the country free of tobacco by 2030.

\section{CONCLUSION}

Tobacco control has been a global health priority. Brief interventions by professionals and specialists may reinforce and motivate the tobacco users to quit tobacco dramatically. We are in a position to serve as a tobacco-free role model for the general public. Therefore, by implementing populationbased smoking cessation programs at primary health care, we might ensure help in preventing, initiating and progression of periodontal diseases and other systemic diseases. Ultimately, this will influence in reducing the economic and social burden inflicted by tobacco use on oral and general health.

\section{REFERENCES}

1. Warnakulasuriya S, Dietrich T, Bornstein MM, Casals Peidro E, Preshaw PM, Walter C, et al. Oral health risks of tobacco use and effects of cessation. Int Dent J. 2010;60(1):7-30.

2. Ramseier CA, Warnakulasuriya S, Needleman IG, Gallagher JE, Lahtinen A, Ainamo A, et al. Consensus Report: 2nd European Workshop on Tobacco Use Prevention and Cessation for Oral Health Professionals. Int Dent J. 2010;60(1):3-6.

3. Bilano V, Gilmour S, Moffiet T, d'Espaignet ET, Stevens GA, Commar A, et al. Global trends and projections for tobacco use, 19902025: an analysis of smoking indicators from the WHO Comprehensive Information Systems for Tobacco Control. Lancet. 2015 Mar 14;385(9972):966-76.

4. Helping People Quit Tobacco: A Manual for Doctors and Dentists. WHO Regional Office for South-East Asia; 2010. Available from: http://www.nimhans.kar.nic.in/./Doctors_and_dentists_tobacco_ cessation.pdf.

5. McCann MF, Macpherson LM, Gibson J. The role of the general dental practitioner in detection and prevention of oral cancer: a review of the literature. Dent Update. 2000;27(8):404-8.

6. Johnson GK, Hill M. Cigarette smoking and the periodontal patient. J Periodontol. 2004;75(2):196-209.

7. Tomar SL, Asma S. Smoking-attributable periodontitis in the United States: findings from NHANES III. National Health and Nutrition Examination Survey. J Periodontol. 2000;71(5):743-51.

8. Omana-Cepeda C, Jane-Salas E, Estrugo-Devesa A, Chimenos-Kustner E, Lopez-Lopez J. Effectiveness of dentist's intervention in smoking cessation: A review. J Clin Exp Dent. 2016;8(1):e78-83.

9. Susin C, Oppermann RV, Haugejorden O, Albandar JM. Periodontal attachment loss attributable to cigarette smoking in an urban Brazilian population. J Clin Periodontol. 2004 ;31(11):951-8.

10. Pindborg JJ. Tobacco and gingivitis: statistical examination of the significance of tobacco in the development of ulceromembranous gingivitis and in the formation of calculus. J Dent Res. 1947;26(3):261-4.

11. Genco RJ, Borgnakke WS. Risk factors for periodontal disease. Periodontol 2000. 2013 ;62(1):59-94.

12. Nociti FH, Jr., Casati MZ, Duarte PM. Current perspective of the impact of smoking on the progression and treatment of periodontitis. Periodontol 2000. 2015;67(1):187-210

13. Johnson GK, Guthmiller JM. The impact of cigarette smoking on periodontal disease and treatment. Periodontol 2000. 2007;44:178-94.

14. Bergstrom J, Eliasson S, Dock J. A 10-year prospective study of tobacco smoking and periodontal health. J Periodontol. 2000;71(8):133847.

15. Haas AN, Wagner MC, Oppermann RV, Rosing CK, Albandar JM, Susin C. Risk factors for the progression of periodontal attachment loss: a 5-year population-based study in South Brazil. J Clin Periodontol. 2014;41(3):215-23.

16. Bolin A, Eklund G, Frithiof L, Lavstedt S. The effect of changed smoking habits on marginal alveolar bone loss. A longitudinal study. Swed Dent J. 1993;17(5):211-6.

17. Grossi SG, Genco RJ, Machtei EE, Ho AW, Koch G, Dunford R, et al. Assessment of risk for periodontal disease. II. Risk indicators for alveolar bone loss. J Periodontol. 1995;66(1):23-9.

18. Dietrich T, Maserejian NN, Joshipura KJ, Krall EA, Garcia RI. Tobacco use and incidence of tooth loss among US male health professionals J Dent Res. 2007;86(4):373-7. 
19. Grossi SG, Zambon JJ, Ho AW, Koch G, Dunford RG, Machtei EE, et al. Assessment of risk for periodontal disease. I. Risk indicators for attachment loss. J Periodontol. 1994;65(3):260-7.

20. Machuca G, Rosales I, Lacalle JR, Machuca C, Bullon P. Effect of cigarette smoking on periodontal status of healthy young adults. J Periodontol. 2000;71(1):73-8.

21. Bain CA. Smoking and implant failure--benefits of a smoking cessation protocol. Int J Oral Maxillofac Implants. 1996;11(6):756-9.

22. Darby IB, Hodge PJ, Riggio MP, Kinane DF. Microbial comparison of smoker and non-smoker adult and early-onset periodontitis patients by polymerase chain reaction. J Clin Periodontol. 2000;27(6):417-24.

23. Apatzidou DA, Riggio MP, Kinane DF. Impact of smoking on the clinical, microbiological and immunological parameters of adult patients with periodontitis. J Clin Periodontol. 2005;32(9):973-83.

24. Salvi GE, Ramseier CA, Kandylaki M, Sigrist L, Awedowa E, Lang NP. Experimental gingivitis in cigarette smokers: a clinical and microbiological study. J Clin Periodontol. 2005 ;32(5):441-7.

25. van Winkelhoff AJ, Bosch-Tijhof CJ, Winkel EG, van der Reijden WA. Smoking affects the subgingival microflora in periodontitis. J Periodontol. 2001;72(5):666-71.

26. Hanioka T, Tanaka M, Takaya K, Matsumori Y, Shizukuishi S. Pocket oxygen tension in smokers and non-smokers with periodontal disease. J Periodontol. 2000;71(4):550-4.

27. Eggert FM, McLeod MH, Flowerdew G. Effects of smoking and treatment status on periodontal bacteria: evidence that smoking influences control of periodontal bacteria at the mucosal surface of the gingival crevice. J Periodontol. 2001;72(9):1210-20.

28. Haffajee AD, Socransky SS. Relationship of cigarette smoking to the subgingival microbiota. J Clin Periodontol. 2001;28(5):377-88.

29. Bergstrom J, Persson L, Preber H. Influence of cigarette smoking on vascular reaction during experimental gingivitis. Scand J Dent Res. 1988;96(1):34-9.

30. Mirbod SM, Ahing SI, Pruthi VK. Immunohistochemical study of vestibular gingival blood vessel density and internal circumference in smokers and non-smokers. J Periodontol. 2001;72(10):1318-23.

31. Pauletto NC, Liede K, Nieminen A, Larjava H, Uitto VJ. Effect of cigarette smoking on oral elastase activity in adult periodontitis patients. J Periodontol. 2000;71(1):58-62.

32. Ryder MI, Fujitaki R, Lebus S, Mahboub M, Faia B, Muhaimin D, et al. Alterations of neutrophil L-selectin and CD18 expression by tobacco smoke: implications for periodontal diseases. J Periodontal Res. 1998;33(6):359-68.

33. Scott DA, Stapleton JA, Wilson RF, Sutherland G, Palmer RM, Coward PY, et al. Dramatic decline in circulating intercellular adhesion molecule-1 concentration on quitting tobacco smoking. Blood Cells Mol Dis. 2000;26(3):255-8.

34. Palmer RM, Scott DA, Meekin TN, Poston RN, Odell EW, Wilson RF. Potential mechanisms of susceptibility to periodontitis in tobacco smokers. J Periodontal Res. 1999 ;34(7):363-9.

35. Giannopoulou C, Cappuyns I, Mombelli A. Effect of smoking on gingival crevicular fluid cytokine profile during experimental gingivitis. J Clin Periodontol. 2003;30(11):996-1002.

36. Morozumi T, Kubota T, Sugita N, Itagaki M, Yoshie H. Alterations of gene expression in human neutrophils induced by smoking cessation. J Clin Periodontol. 2004;31(12):1110-6.

37. Cesar-Neto JB, Duarte PM, de Oliveira MC, Tambeli CH, Sallum EA, Nociti FH, Jr. Smoking modulates interleukin-6:interleukin-10 and RANKL:osteoprotegerin ratios in the periodontal tissues. J Periodontal Res. 2007;42(2):184-91.

38. Quinn SM, Zhang JB, Gunsolley JC, Schenkein HA, Tew JG. The influence of smoking and race on adult periodontitis and serum IgG2 levels. J Periodontol. 1998;69(2):171-7.

39. Tollerud DJ, Clark JW, Brown LM, Neuland CY, Mann DL, Pankiw-Trost LK, et al. Association of cigarette smoking with decreased numbers of circulating natural killer cells. Am Rev Respir Dis. 1989;139(1):194-8.

40. Tipton DA, Dabbous MK. Effects of nicotine on proliferation and extracellular matrix production of human gingival fibroblasts in vitro. J Periodontol. 1995;66(12):1056-64.

41. Gamal AY, Bayomy MM. Effect of cigarette smoking on human PDL fibroblasts attachment to periodontally involved root surfaces in vitro. J Clin Periodontol. 2002;29(8):763-70.

42. D'Aiuto F, Ready D, Parkar M, Tonetti MS. Relative contribution of patient-, tooth-, and site-associated variability on the clinical outcomes of subgingival debridement. I. Probing depths. J Periodontol. 2005;76(3):398-405.

43. Grossi SG, Zambon J, Machtei EE, Schifferle R, Andreana S, Genco RJ, et al. Effects of smoking and smoking cessation on healing after mechanical periodontal therapy. J Am Dent Assoc. 1997;128(5):599-607.

44. Tomasi C, Bertelle A, Dellasega E, Wennstrom JL. Full-mouth ultrasonic debridement and risk of disease recurrence: a 1-year follow-up. J Clin Periodontol. 2006;33(9):626-31.

45. Kotsakis GA, Javed F, Hinrichs JE, Karoussis IK, Romanos GE. Impact of cigarette smoking on clinical outcomes of periodontal flap surgical procedures: a systematic review and meta-analysis. J Periodontol. 2015;86(2):254-63.

46. Bowers GM, Schallhorn RG, McClain PK, Morrison GM, Morgan R, Reynolds MA. Factors influencing the outcome of regenerative therapy in mandibular Class II furcations: Part I. J Periodontol. 2003;74(9):1255-68.

47. Lindfors LT, Tervonen EA, Sandor GK, Ylikontiola LP. Guided bone regeneration using a titanium-reinforced ePTFE membrane and particulate autogenous bone: the effect of smoking and membrane exposure. Oral Surg Oral Med Oral Pathol Oral Radiol Endod. 2010;109(6):825-30.

48. Patel RA, Wilson RF, Palmer RM. The effect of smoking on periodontal bone regeneration: a systematic review and meta-analysis. J Periodontol. 2012;83(2):143-55.

49. Andia DC, Martins AG, Casati MZ, Sallum EA, Nociti FH. Root coverage outcome may be affected by heavy smoking: a 2-year follow-up study. J Periodontol. 2008;79(4):647-53.

50. Strietzel FP, Reichart PA, Kale A, Kulkarni M, Wegner B, Kuchler I. Smoking interferes with the prognosis of dental implant treatment: a systematic review and meta-analysis. J Clin Periodontol. 2007;34(6):523-44.

51. Cortellini P, Paolo G, Prato P, Tonetti MS. Long-term stability of clinical attachment following guided tissue regeneration and conventional therapy. J Clin Periodontol. 1996;23(2):106-11. 
52. Albandar JM, Streckfus CF, Adesanya MR, Winn DM. Cigar, pipe, and cigarette smoking as risk factors for periodontal disease and tooth loss. J Periodontol. 2000;71(12):1874-81.

53. Krall EA, Garvey AJ, Garcia RI. Alveolar bone loss and tooth loss in male cigar and pipe smokers. J Am Dent Assoc. 1999;130(1):57-64.

54. Natto S, Baljoon M, Bergstrom J. Tobacco smoking and periodontal health in a Saudi Arabian population. J Periodontol. 2005;76(11):191926.

55. Robertson PB, Walsh M, Greene J, Ernster V, Grady D, Hauck W. Periodontal effects associated with the use of smokeless tobacco. J Periodontol. 1990;61(7):438-43.

56. Fisher MA, Taylor GW, Tilashalski KR. Smokeless tobacco and severe active periodontal disease, NHANES III. J Dent Res. 2005;84(8):70510.

57. Boffetta P, Hecht S, Gray N, Gupta P, Straif K. Smokeless tobacco and cancer. Lancet Oncol. 2008;9(7):667-75.

58. Nair P, Sutherland G, Palmer RM, Wilson RF, Scott DA. Gingival bleeding on probing increases after quitting smoking. J Clin Periodontol. 2003;30(5):435-7.

59. Krall EA, Dietrich T, Nunn ME, Garcia RI. Risk of tooth loss after cigarette smoking cessation. Prev Chronic Dis. 2006;3(4):A115.

60. Dietrich T, Walter C, Oluwagbemigun K, Bergmann M, Pischon T, Pischon N, et al. Smoking, Smoking Cessation, and Risk of Tooth Loss: The EPIC-Potsdam Study. J Dent Res. 2015 ;94(10):1369-75.

61. Haber J, Kent RL. Cigarette smoking in a periodontal practice. J Periodontol. 1992;63(2):100-6.

62. Kinane DF, Chestnutt IG. Smoking and periodontal disease. Crit Rev Oral Biol Med. 2000;11(3):356-65.

63. Rosa EF, Corraini P, de Carvalho VF, Inoue G, Gomes EF, Lotufo JP, et al. A prospective 12-month study of the effect of smoking cessation on periodontal clinical parameters. J Clin Periodontol. 2011;38(6):562-71.

64. Preshaw PM, Heasman L, Stacey F, Steen N, McCracken GI, Heasman PA. The effect of quitting smoking on chronic periodontitis. J Clin Periodontol. 2005;32(8):869-79.

65. Fullmer SC, Preshaw PM, Heasman PA, Kumar PS. Smoking cessation alters subgingival microbial recolonization. J Dent Res. 2009;88(6):524-8.

66. Bostrom L, Linder LE, Bergstrom J. Influence of smoking on the outcome of periodontal surgery. A 5-year follow-up. J Clin Periodontol. 1998;25(3):194-201

67. Gordon JS, Lichtenstein E, Severson HH, Andrews JA. Tobacco cessation in dental settings: research findings and future directions. Drug Alcohol Rev. 2006;25(1):27-37.

68. Agaku IT, Ayo-Yusuf OA, Vardavas CI. A comparison of cessation counseling received by current smokers at US dentist and physician offices during 2010-2011. Am J Public Health. 2014;104(8):e67-75.

69. Chaffee BW, Couch ET, Ryder MI. The tobacco-using periodontal patient: role of the dental practitioner in tobacco cessation and periodontal disease management. Periodontol 2000. 2016;71(1):52-64.

70. Tobacco Use and Dependence Guideline Panel. Treating Tobacco Use and Dependence: 2008 Update. Rockville (MD): US Department of Health and Human Services; 2008 May. 3, Clinical Interventions for Tobacco Use and Dependence. Available from: https://www.ncbi. nlm.nih.gov/books/NBK63948/

71. Treating tobacco use and dependence: 2008 update. Clinical practice guideline. Rockville, MD: US Department of Health and Human Services, Public Health Service; 2008 ( https://www.ahrq.gov/sites/default/files/wysiwyg/professionals/clinicians-providers/ guidelines-recommendations/tobacco/clinicians/update/treating_tobacco_use08.pdf, accessed 25 June 2017).

72. Lichtenstein E, Zhu SH, Tedeschi GJ. Smoking cessation quitlines: an underrecognized intervention success story. Am Psychol. 2010;65(4):252-61.

73. WHO Framework Convention on Tobacco Control: guidelines for implementation: Article 5.3, Article 8, Articles 9 and 10, Article 11, Article 12, Article 13, Article 14. Geneva: World Health Organization; 2013 (http://www.who.int/fctc/guidelines/adopted/guidel_2011/ en).

74. Stead LF, Perera R, Bullen C, Mant D, Hartmann-Boyce J, Cahill K, et al. Nicotine replacement therapy for smoking cessation. Cochrane Database Syst Rev. 2012;11:CD000146.

75. Gourlay SG MJ. Antismoking products. Medical Journal of Australia 1990;153:699-707.

76. Zambon P, Talamini R, La Vecchia C, Dal Maso L, Negri E, Tognazzo S, et al. Smoking, type of alcoholic beverage and squamous-cell oesophageal cancer in northern Italy. Int J Cancer. 2000;86(1):144-9. 